was director (see p. 112 of this issue). The work has been largely on stellar spectroscopy. Since 1936 the principal lines of work have been the development of methods of measuring stellar gradients and colour temperatures, using the McLean prismatic camera, and a photographic survey of galactic clusters made with the Mond telescope. New ground has been broken in recent years with the initiation of photometric research on the twilight luminescence of atmospheric sodium. The Kensington telescope has been used to study the irregular variable star, $\gamma$-Cassiopeiæ; there are some 460 spectrograms of this star in an almost unbroken sequence from 1921 to 1956 .

The Observatory was, and is, maintained as a nonprofit making corporation through endowments and funds provided by donors. Since 1948 the management has been vested in the Council of the Corporation on which the University of Exeter has a definitive majority. The funds available have never been lavish. Rapidly rising costs since the War, together with the development of sophisticated experimental techniques, have meant that the position of the Observatory as an effective centre of original research has become progressively more difficult and indeed critical. Against the background of developments in satellites and in space research, the extensive recent progress of studies of the upper atmosphere and the revival of interest in astronomy and astrophysics, such a difficult position presents an obvious challenge. The site is large enough for astrophysical work and for an extensive programme of research and teaching in geophysics, a growing interest of the University's Department of Physics, and of geomagnetism, an interest of the Department of Mathematics.

The first immediate change of activity for the Observatory will follow from the interests of Dr. $\mathrm{K}$. Weekes and Mr. A. Nichol. Conditions in the high atmosphere can be studied by various means using both radio and optical techniques. Up to the height of the greatest electron concentration in the $F_{2}$ region it is possible, in principle, to infer the distribution of ionization from routine soundings.
Above the peak of the $F_{2}$ region, artificial satellites may be used, or Thomson scattering of radio waves and optical experiments. An examination of the radio waves emitted by satellites may be used to infer the integrated electron density between the receiver and the satellite. This is relatively insensitive to the distribution of electrons, but as the satellite changes height in the course of a transit, the distribution at satellite height may be inferred. The most valuable direct means of studying the distribution of electrons in the high atmosphere is by the Thomson scattering of radio waves by free electrons. Examination of experiments in the United States to heights of about $700 \mathrm{~km}$. suggests that useful results should be obtained to a height of about $2,000 \mathrm{~km}$. It is commonly believed that the emission lines of OI at 6300 and $6364 \AA$. are excited by recombination in the $F$ region. The correlation between the optical intensities and radio measurements of ionization clearly must be examined. Moreover, it is possible, with careful techniques, to measure the line-width of the OI lines and so obtain a direct measure of the temperature of the atmosphere at the height of emission of these lines.

To a classical astronomer nowadays anything below a fixed star is no doubt to be termed 'terrestrial', just as to many people any study above roof-level is termed 'astronomical'. The future is seen to lie in the wedding of optical with radio techniques in the fields of astrophysics and geophysics and of geomagnetism. Moreover, the vitality of the Observa tory has suffered from its relative isolation. The University did indeed, so Gregory said, acquire "a possession which is unequalled in any but the older universities". The means are there to train students and research workers in the old and in the new techniques of exploring space. The raw material of research is to hand. The Observatory began as Lockyer's hobby in his old age: it has acquired a reputation in astrophysics and an affectionate regard in the south-west of England. By acquiring additional eyes we shall see more and see farther. An old man's hobby has become a young University's opportunity.

\title{
LONG-RANGE RADIO COMMUNICATION BY SATELLITE MICROWAVE DIPOLES
}

\begin{abstract}
$\mathrm{A}^{\mathrm{N}}$ $\mathrm{N}$ article under this title detailing the West Ford Project was published in Nature of September 23, p. 1237. At the eleventh General Assembly of the International Astronomical Union held in Berkeley, California, on August 24, two resolutions were unanimously adopted concerning that Project and similar space experiments that might have harmful effects on astronomy. At the recent General Assembly of the International Council of Scientific Unions in London, a resolution similar to Resolution No. 1 of the International Astronomical Union was adopted, which refers to the whole of science, rather than to astronomy in particular.

The following is the text of the resolutions adopted by the International Astronomical Union:

Resolution No. 1. Viewing with great concern the grave danger that some future space projects might seriously interfere with astronomical observations in the optical as well as in the radio domain,

and believing that a degree of contamination of space which at the present time would be hardly
\end{abstract}

detectable, might, if long-lived, well be disastrous to future observations with improved techniques, and maintaining that no group has the right to change the Earth's environment in any significant way without full international study and agreement; the International Astronomical Union gives clear warning of the grave moral and material consequences which could stem from a disregard of the future of astronomical progress,

and appeals to all Governments concerned with launching space experiments which could possibly affect astronomical research to consult with the International Astronomical Union before undertaking such experiments and to refrain from launching until it is established beyond doubt that no damage will be done to astronomical research.

Resolution 2. The International Astronomical Union expresses its appreciation that the plans for Project West Ford have been publicly announced well ahead of proposed launching and of the United States Government's official policy* that further 
launchings will be guided by the principle that such projects shall not be undertaken unless sufficient safeguards have been obtained against harmful interference with astronomical observations.

Nevertheless the International Astronomical Union views with the utmost concern the possibility that the band of dipoles proposed in Project West Ford might be long-lived, and it is completely opposed to the experiment until the question of permanence is clearly settled in published scientific papers with adequate time being allowed for their study. The International Astronomical Union is opposed to any experiment which might hamper future developments in astronomy.

If a short lifetime for the dipoles and the harmless nature of the experiment can be assured, and if Project West Ford is carried out, the International Astronomical Union regards it as essential that the fullest observations of, and experiments on, the properties and behaviour of the band of dipoles be carried out by all possible means. The observations and experiments should be performed and analysed according to the highest scientific standards and with the best equipment available, bearing in mind that signals which are barely, or not, detectable to-day will probably cause serious interference with future scientific research because of the development of more sensitive equipment.
The observations and experiments to be made on West Ford are likely to be difficult to perform, and will, in many ways, be similar to those carried out by the authorities responsible for operating West Ford. Moreover, much specific information such as precise and up-to-date ephemerides will be required. The International Astronomical Union will attempt to arrange for rapid and full co-operation among astronomers making observations and calculations, and to provide for world-wide dissemination of their results conforming to accepted standards of scientific research.

The International Astronomical Union welcomes the position* taken by the Government of the United States that any decision on later experiments of the West Ford type will be taken in the light of the results obtained from the presently proposed experiment. To enable the International Astronomical Union to obtain the necessary data, it requests the Government of the United States to grant full privileges to a group of astronomers, acceptable both to the Government and to the Union, to co-operate with West Ford authorities in performing quantitative experiments to determine the properties of the proposed belt of dipoles, its changes with time and location, and its impact upon present and future astronomical research.

* Letter of August 11, 1961, from Dr. J. B. Wiesner to Dr. L. V. Berkner.

\section{THE SWEDISH SEED ASSOCIATION}

$\mathrm{T}$ HE title traditionally given in English translations to the Sveriges Utsädesförening does not perhaps fully indicate the scope of the scientific work in this pioneer research station.

Throughout its development the Swedish Seed Association has had strong support from both farmers and scientists, and when the seventy-fifth anniversary of the Association was celebrated in July 1961, King Gustav VI Adolf welcomed a large attendance of members living within reach of each of the eight branch stations as well as growers and technicians who are directly in touch with the work at the Svalof headquarters.

Founded in 1886 as a co-operative association of farmers on the initiative of Birger Welinder, who farmed at Svalöf, it reflected a big increase in interest in crop-husbandry problems. During the extension of the arable cropping area in the middle of the nineteenth century Swedish farmers had come to realize that the severity of the winter, the relatively long days and the short summers made demands which could not be met by even the best of the foreign varieties.

From the beginning the pioneer plant breeders at Svalof fought hard to convince the large body of farmers and seed growers of the importance of using the best scientific techniques in the improvement of crops. As the programme developed under Profs. Hj. Nilsson, N. H. Nilsson-Ehle, A. Akerman and other distinguished scientists and agronomists it became clear that improved crop varieties could best be obtained through an active programme of research some of which must be of a fundamental nature.

\section{Cytogenetic Research}

Practical breeding work is undertaken at Svalöf on the herbage crops, oil and fibre crops, and the root crops for fodder production as well as on the four main cereals.
For this breeding work material is provided mainly from three sources :

(1) By the introduction of valuable genes from primitive forms or wild species, or from cultivated varieties with special characteristics. One of the most marked features at Svalof is the importance attached to collaboration with crop improvement and other research stations in foreign countries. Valuable plant material has been obtained from a wide range of countries either by exchange or by plant collecting expeditions.

(2) By inducing mutations. The Swedish workers are effectively using this technique to increase the genetic variability of the cultivated varieties and breeding material with which they are working.

(3) By increasing the chromosome number through auto- and allo-polyploidy, thus offering new possibilities for the development of new genotypes. Especially promising are the polyploids of red and white clover, rye and turnips. (Oil rape is an important crop in Sweden. By crossing artificially induced polyploids of turnip rape and different types of kale, new high-yielding and hardy varieties of winter rape are being developed.)

Research of a more fundamental nature is in progress to ascertain the causes of reduced fertility in artificial polyploids and to investigate different methods of using polyploids in breeding programmes.

In the development of polyploids the work at Svalof has benefited greatly from the close cooperation of Prof. A. Müntzing at the Institute of Genetics situated a few miles away in the University of Lund, and similarly with Prof. A. Gustafsson on induced mutations in barley and other crops. Mutations have been induced in smooth-stalk meadow grass which have brought a return to eross-fertilization as the means of reproduction in place of apomixis. 